The BDJ News section accepts items that include general news, latest research and diary events that interest our readers. Press releases or articles may be edited, and should include a colour photograph if possible. Please direct your correspondence to the News Editor, Arveen Bajaj at the BDJ, The Macmillan Building, 4 Crinan Street, London N19XW or by email to bdj@bda.org

\section{Study says journal based learning is effective}

Journal based
learning app-
ears to be an
effective way
of undertaking
verifiable Con-
tinuing Profes-
sional Devel-
opment (CPD),
according to a
survey to be
published in

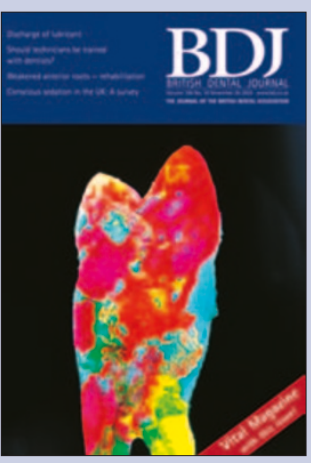

the next issue

of the British Dental Journal (BDJ). In the survey, four hundred dentists who had registered to undertake CPD with the $B D J$ were randomly selected and sent a questionnaire. Around $87 \%$ said that the $B D J C P D$ satisfied their personal CPD needs while 92\% said that their knowledge has been increased as a result of undertaking the initiative. Over $70 \%$ added that an element of their clinical practice had changed as a result of undertaking the $B D J$ CPD.

The life-long learning initiative requires all registered dentists in the UK to engage in 250 hours of continuing professional development over a five year period, at least 75 hours of which should be 'verifiable' - that is defined as having concise educational aims and objectives, clear anticipated outcomes and identified quality control mechanisms. In July 2003 the BDJ in partnership with Eastman Continuing Professional Development established a new CPD programme to enable all UK dental practitioners to collect a maximum of 48 hours of verifiable CPD per annum. Each issue of the $B D J$ now contains two papers that have been selected for verifiable CPD, with four multiple choice questions linked to each article. Practitioners receive one verifiable CPD hour per paper, giving a potential total of two CPD hours per $B D J$ issue.

\title{
Dental team raises cash for Cancer Research
}

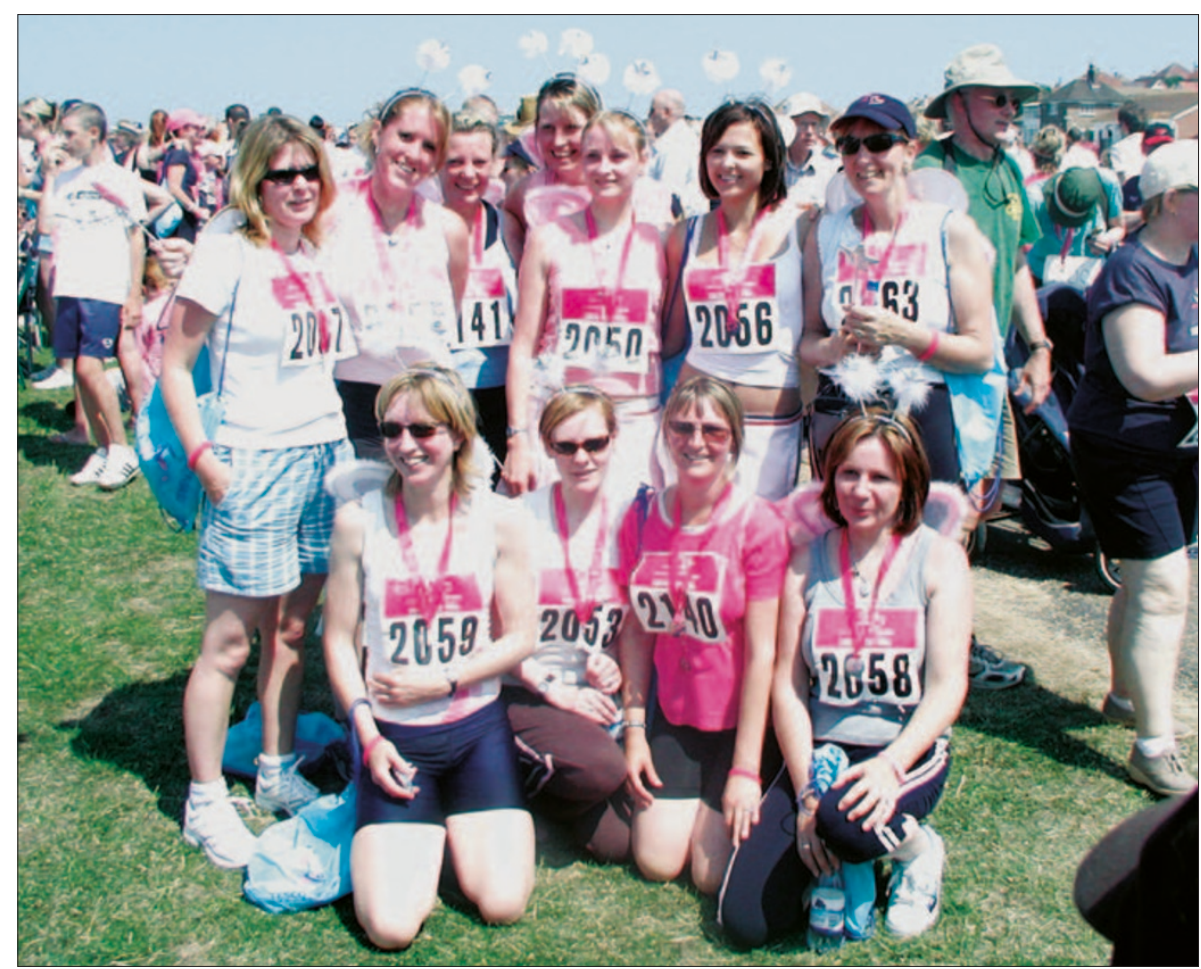

Dental team members from Chris Lewns' Implant and Dental Centre in Whitstable, Kent took part in the Canterbury area's 'Race for Life' in support of Cancer Research earlier this year. The team chose the name 'The Tooth Fairies,' and under the captaincy of Chris' wife Kate raised over $€ 1,400$ for Cancer Research. Cancer Research is a cause very close to their hearts, as in 2000 Chris was himself diagnosed with cancer, and with a poor prognosis. Happily he won through, thanks to the intervention of some highly skilled surgeons at the Royal Marsden and Brompton Hospitals in London.

\section{Appeal for helping homeless at Christmas}

Crisis, the national homelessness charity, is urgently appealing for dentists, dental nurses and hygienists to volunteer their skills to help homeless people this Christmas.

Up to 1,500 homeless and vulnerably housed people will visit the 34th Crisis Open Christmas this year.

Some will be rough sleepers but the majority will be hidden homeless people who may stay in hostels, bed and breakfast accommodation or on the floors of friends and families.

Held at six venues across London, the Crisis Open Christmas is a gateway to opportunity for homeless people. It pro- vides access to a range of essential health, accommodation, work and learning support as well as companionship.

Dentistry is an integral part of the medical services on offer and many guests may not have had dental services for some time. Dentists, dental nurses and hygienists are urgently needed to volunteer for a range of shifts between 23rd and 30th December inclusive.

To volunteer, call 02074263874 for an application form, apply online at www.crisis.org.uk or email volunteering@crisis.org.uk . For more information call 0207426 3875/2. 


\section{Raising awareness of mouth cancer}

The British Dental Health Foundation is appealing for dentists to help halt the growing number of mouth cancer deaths by educating their patients on the main symptoms and risk factors. The plea for help is being issued in this year's Mouth Cancer Awareness Week. Running between November 13 and 19, the campaign is using the tagline 'It Could Be You' to demonstrate that the condition can strike anyone at any time.

The charity claims that mouth cancer kills one person every five hours in the UK and that the most common causes of mouth cancer are smoking and drinking alcohol to excess.

However, as around 25\% of mouth cancer cases in younger people present none of the common risk factors, patients should be taught to be aware of possible symptoms too.

Dr Nigel Carter, chief executive of the British Dental Health Foundation, commented, "According to research by the Foundation, half of people over the age of 45 claims never to have been checked for mouth cancer by a dentist. While this doesn't necessarily mean people are not being checked it does prove that dentists are not making patients aware of it."

He urged dentists to use Mouth Cancer Awareness Week to start making patients aware of the dangers of mouth cancer and as an opportunity to educate them on the risk factors and symptoms of the dis-

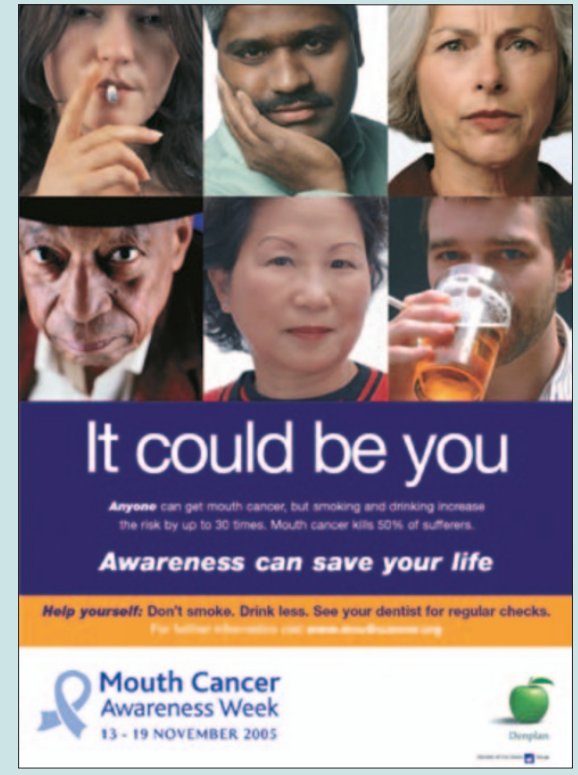

ease such as smoking, alcohol and poor diet.

Dr Carter continued, "Regular screenings should take place throughout the year, not just during Mouth Cancer Awareness Week."

The free Mouth Cancer Awareness Week guide contains information on the condition, ideas for events and a guide to useful resources.

It also contains details on how to claim your free poster from Denplan. Visit www.mouthcancer.org for more information.

\section{Mouths prefer fatty foods}

A sensor in the mouth promotes preference for fatty foods, according to a study in November's issue of the Journal of Clinical Investigation. The study suggests that the sense of taste informs the organism about the quality of ingested food. It comprises five sub-modalities that perceive sweet, salt, sour, bitter, and umami stimuli. The possibility for an additional taste modality directed to lipid has often been suggested because many animals exhibit a spontaneous attraction for fats, but the existence of an actual sensor remained a matter of debate. In the study, CD36 involvement in orosensory detection of dietary lipids : impact on spontaneous fat preference and digestive secretions, researchers Phillipe Besnard and colleagues identify the first candi- date for lipid detection in the oral cavity. The authors combine genetic, morphological, behavioural and physiological approaches to pinpoint the multifunctional glycoprotein CD36 (also termed fatty acid transporter, FAT) as the sensor for fat. They show that lingual stimulation of CD36 by fatty acids influences behavioural and digestive physiology. CD36 gene inactivation fully abolishes both the spontaneous preference for fat and the changes in gastrointenstinal secretions mediated by oral delivery of lipids. These findings unveil one potential pathway mediating fat taste. They claim that the data suggest that an alteration in the fat perception system might increase obesity risk through feeding dysregulation.

\section{Mouth cancer advice issued}

The Dental Defence Union (DDU), specialist dental division of the Medical Defence Union, has issued advice for dentists to help them avoid delay in obtaining specialist treatment for patients who may show the early signs of mouth cancer. The advice is timed to coincide with this year's Mouth Cancer Awareness Week, which takes place 13-19 November 2005.

The risk management advice includes; if there is no obvious problem but the patient continues to complain of soreness, be prepared to discuss with colleagues and investigate further and if you suspect an abnormality, you should make an immediate referral to an appropriate specialist for further investigation, which will usually involve a biopsy. Retain a dated copy of your referral letter.

The organisation advises ensuring that any referral has been accepted and that the patient is sent a consultation appointment. In addition, the patient should be informed of how long they can expect to wait before receiving an appointment and be advised to call should there be any delays.

Mark Phillips, dento-legal adviser at the DDU commented: "Many dentists already carry out soft tissue checks for the early signs of oral cancer as part of a routine examination and most cases of oral cancer can be picked up this way. It is important that dentists are aware of the need to check for indications of mouth cancer and if they find anything suspicious, make an immediate referral of the patient for specialist care."

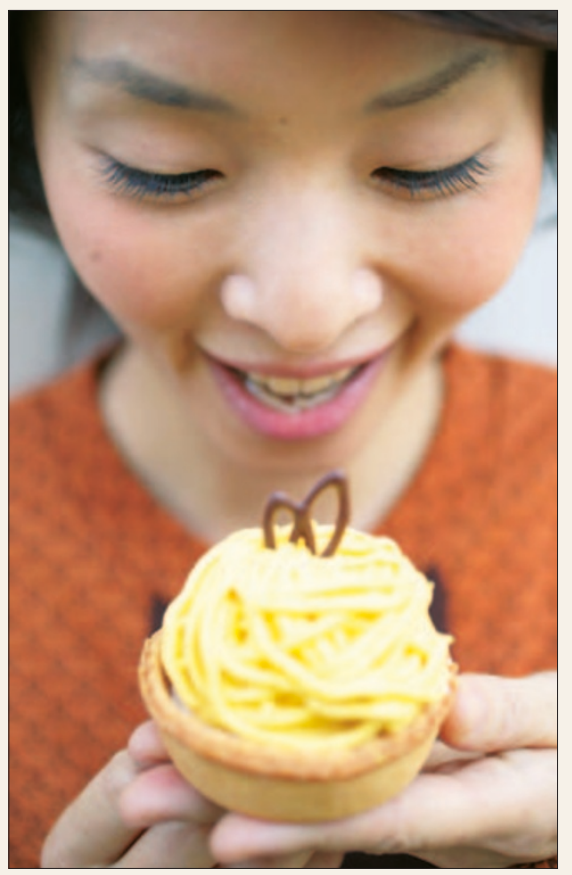




\section{Reducing treatment side effects for head and neck cancer}

Results from a University of Pittsburgh study evaluating intensity modulated radiation therapy (IMRT) for head and neck cancer has determined the ideal doses for lessening treatment side effects. The findings were presented at the 47th Annual Meeting of the American Society for Therapeutic Radiology and Oncology (ASTRO) in Denver.

"Despite major advances in chemotherapy and radiation for the treatment of head and neck cancers, many patients continue to suffer debilitating side effects that greatly impact their quality of life," said Dwight E. Heron, M.D., study co-author and associate professor of radiation oncology, University of Pittsburgh School of Medicine. "While these high-energy beams are targeted to the tumour site as precisely as possible, they often inadvertently injure healthy tissue that surrounds the tumour site, limiting the doses of radiation that can be used to effectively destroy cancer cells. With this study, we sought to discover whether tightly focused radiation beams, such as those provided by IMRT, would make a difference in the severity of side effects associated with treatment and found a distinct dose-response relationship in the oral cavity of patients treated with IMRT in addition to chemotherapy."

In the study, 70 patients with head and neck cancer were treated with IMRT using the Eclipseâ Planning System, Varian Medical Systems and chemotherapy. Patients were treated from April 2002 through September 2004 and were evaluated for grade level of oral mucositis, or inflammation, with severe cases may require tube feeding. can be significant."



based on the volume of IMRT dose administered. Oral mucositis not only causes pain, but can also affect speech, the ability to eat or drink and to take oral medication. Patients

Results indicated that the severity of side effects, or the grade of oral mucositis, was directly correlated with the volume of the radiation dose administered to the oral cavity, and the researchers defined an ideal dose volume of IMRT at which the incidence of acute oral mucositis was lessened.

"We found that if we constrain the dose of IMRT, we reduce the toxic effects of treatment," said Dr. Heron. "These results are encouraging evidence that head and neck cancer patients can benefit from IMRT at specific doses. With more homogenous and conformal treatment, head and neck cancer patients may be spared side effects from standard radiotherapy that

\section{Oxford dentists form protest groups}

Over 100 Oxfordshire dentists have formed a protest group in reaction to the detail of the new NHS dental contract details so far announced. The dentists, all from mixed practices, met to discuss the implications of the new contract.

Although treating adults privately, to date they have retained NHS services for certain priority groups such as children and/or benefit recipients, accepting that providing such a NHS service is subsidised by their majority private practice. Under the new proposals it is understood that this selective acceptance will no longer be allowed, effectively forcing private practices out of the NHS.

Growing from a conversation between two colleagues, the group quickly grew to eight members in 24 hours and then to 49 following the meeting one week later. Looking after 35,000 NHS patients in total, the dentists have written to the local Primary Care Trust pointing out that if they decide not to take up the new contract these patients will effectively be without access to NHS dental treatment. Local press and media interest spread the word and dentists in south Oxfordshire, the city of Oxford and north Oxfordshire have now joined the protest, swelling the number to over 100 dentists with 75,000 plus patients. Similar reaction in Cambridgeshire has meant that dentists there are poised to de-register thousands of patients in a similar protest.

Thanks to e-mail and Internet discussion groups dentists all around the country are being kept informed of developments as they happen, a facility that simply did not exist at the time prior to the introduction of the last major change of NHS dental contract in 1990/91. The Oxford group are pleased to hear from other colleagues with similar thoughts and may be contacted through Dr Gareth McAleer at Smileatbroadway@aol.com.
November 2005

British Association of Cosmetic Dentistry

2005 Conference

Date: 18-19.11.05

Venue: Victoria Plaza Hotel, London

Tel: 02076124166

Fax: 02071827123

Email: info@bacd.com

www.bacd.com

The Faculty of General Dental Practice: The Evidence Base for Commissioning Primary Dental Care Services

Date: 23.11.05

Venue: Royal College of Surgeons of

England, London

Tel: Amrita Narain 02078696750

Email: anarain@rcseng.ac.uk.

www.fgdp.org.uk

2nd European Congress on the

Reconstruction of the Periodontally Diseased Patient

Date: 25-27.11.05

Venue: Radisson SAS Scandinavia Hotel, Copenhagen

Email: kongress@quintessenz.de www.quintessenz.de/ecrp

Greater New York Dental Meeting

Date: 25-30.11.05

Venue: New York

Email:info@gnydm.com

www.gnydm.com

\section{February 2006}

2nd European Conference of Preventive and Minimally Invasive Dentistry

Date: 23-25.02.06

Venue: Congress Centre Innsbruck, Innsbruck, Austria

E-mail: kongress@quintessenz.de www.quintessenz.de/ecp

28th Asia Pacific Dental Congress

Date: 23-27.02.06

Venue: Expo Centre, Karachi, Pakistan

Email:info@apdcpakistan.com

www.apdcpakistan.com

March 2006

British Society of Periodontology Spring

Conference

Date: 25.03.06

Venue: Keble College, Oxford

Tel/Fax: +44(0)1730 890478

Email: ghilaine.ower@btopenworld.com www.bsperio.org.uk 


\section{Dental volunteers sought for new complaints service}

The General Dental Council (GDC) is looking for volunteers from the dental profession to help resolve complaints from patients about private dental work.

The new Dental Complaints Service, is being set up and will be funded by the GDC.

A dental care professional will sit with lay volunteers on regional complaints panels and hear complaints that cannot otherwise be resolved.

All kinds of dental care professionals are being invited to volunteer to sit on the panels. Gordon Miles, director, explained, "First, we'll encourage dissatisfied patients to complain directly through a dental practice's own complaints scheme. Then our advisers will try to sort out complaints informally with the patient and dental professional concerned. Only if they cannot resolve a complaint will it go to a panel. The aim is to resolve complaints informally - as fairly, efficiently, transparently and quickly as we can. This is an opportunity for dental care professionals to play a role in resolving fellow professionals' disputes, and use their knowledge within a wider forum."

Currently, there is an NHS dental complaints scheme, but private patients - including those who receive treatment from a dental hygienist privately - have limited options. The new service will help resolve complaints that are not

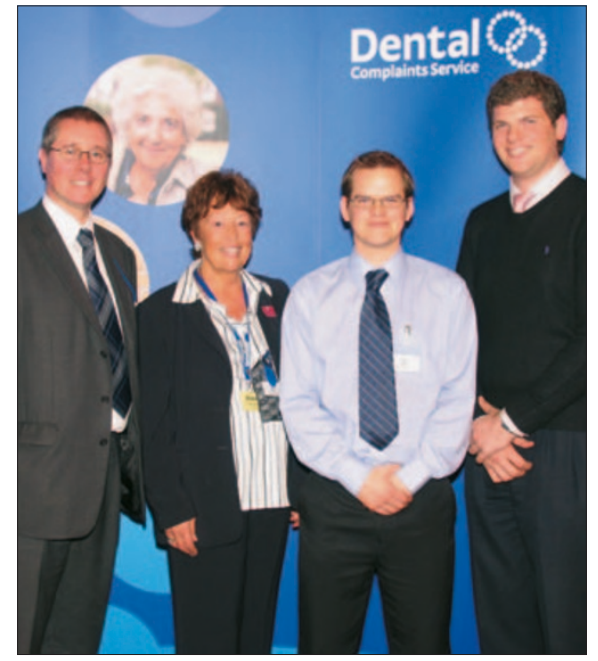

From left to right, Gordon Miles, Director, Meredyth Bell, Council Member GDC, Mark Tempest, Complaints Support Officer , James Paddick, Complaints Manager

about patient safety issues.

A complaint that raises patient safety issues will be referred to the GDC, which will be able to deal with the complaint under its formal conduct procedures, as is the case now.

The Dental Complaints Service is due to be launched next year. To find out more about volunteering to join a complaints panel, call $08456 \quad 120 \quad 540$ or visit the Council's website at www.gdc-uk.org.

\section{Kings student wins award}

A dental student who recently qualified from King's College London Dental Institute has won the British Society of Periodontology Frank Ashley Undergraduate Prize. Payal J. Patel won the prize for her project entitled, The effect of a commercially available mouthwash on human osteoblast cells.

The award, named to honour the memory of Professor Frank Ashley, a former President of the Society, is offered to encourage dental undergraduates to carry out projects related to periodontology. It is open to students at UK Dental Schools and graduates who have qualified within the previous twelve months. Professor Ashley was also a former Dean of the Dental Institute.

Payal was also awarded the Newland Pedley Medal for Operative Dentistry and the Malleson Prize for dental research at this year's graduation ceremony at Southwark Cathedral.

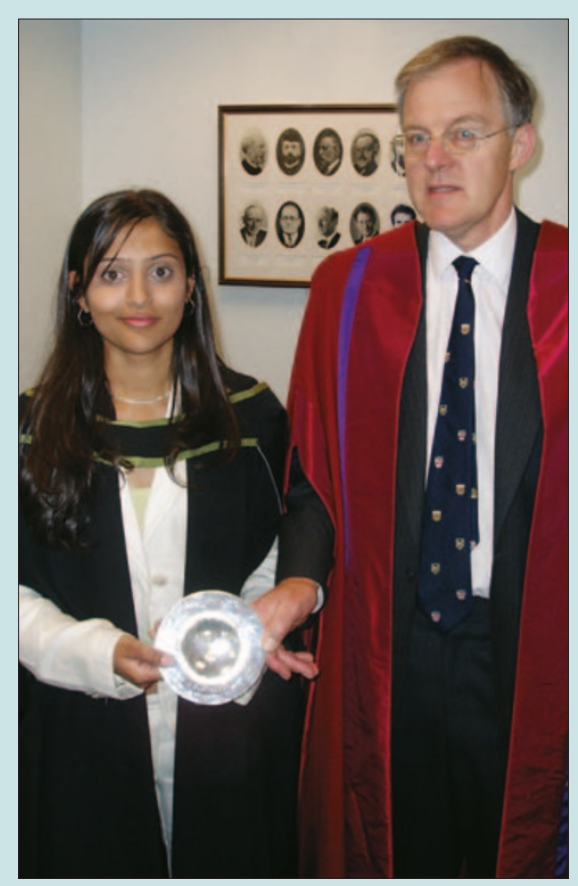

Polish dentists recruited for Scottish patients

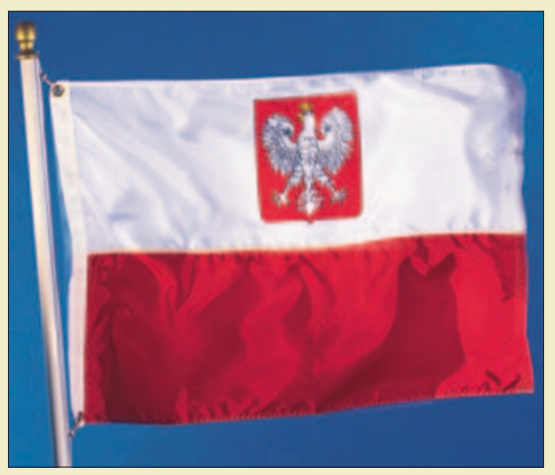

Thirty-two Polish dentists are being recruited to work within the NHS in Scotland, according to the Scottish Health Executive. The first 12 dentists are due to arrive in Scotland by the end of January next year and will provide treatment for around 20,000 patients. Deputy Health Minister Lewis Macdonald also confirmed that several health boards were in discussion with an independent dental corporation to provide NHS dental treatment in areas where there are currently difficulties in accessing NHS services. Many patients were forced to re-register as private patients after their dental practices opted out of the health service.

The contract to bring all the dentists to Scotland was agreed in September 2005.

The first group of 12 dentists will be employed in the salaried service in Fife, Forth Valley and Argyll \&t Clyde while a further 20 Polish dentists are due to arrive in Scotland to take up posts next year.

The British Dental Association (BDA) claimed that the move would simply be a drop in the ocean and would not go far enough to address the problems facing NHS dentistry in Scotland. Dr Andrew Lamb, the BDA's Director for Scotland, said that a longer-term solution to the problems facing NHS dentistry in Scotland could only be achieved through constructive dialogue between the Scottish Executive health department and the BDA. 